\title{
Inhibitors of the Dicarboxylate and Tricarboxylate Transporting Systems of Rat Liver Mitochondria
}

\author{
B. H. Robinson *, G. R. Williams, M. L. Halperin, and C. C. Leznoff \\ Departments of Biochemistry and Medicine, University of Toronto, \\ Toronto 5, Ontario, Canada, and \\ Department of Chemistry, York University, Downsview, Ontario, Canada
}

Summary. A large number of compounds were tested for their effectiveness as inhibitors of the tricarboxylate and dicarboxylate transporting systems of rat liver mitochondria as monitored by citrate $/\left[{ }^{14} \mathrm{C}\right]$ citrate exchange and phosphate $/\left[{ }^{14} \mathrm{C}\right]$ L-malate exchange, respectively. The influence of inhibitor structure on inhibitory potency is discussed for each transporting system and deductions made concerning the nature of the binding sites of these carrier systems.

A number of dicarboxylic acids have been shown to inhibit the dicarboxylate transporting system of rat liver mitochondria. These include 2-butylmalonate [2,6], 2-pentylmalonate [9], 2-p-iodobenzylmalonate [8] and 2-phenylsuccinate $[2,5]$. Similarly a number of tricarboxylic acid analogues of citrate were shown to be inhibitory to the citrate transporting system [10]. Recently, a new inhibitor of citrate transport, 1, 2, 3-benzenetricarboxylate was described [11]. In the course of these recent investigations we had occasion to test the susceptibility of the two above transporting systems to a large number of compounds, to find the best inhibitors to use. The results of this screening are interesting in that they provide some information about the nature of the binding sites of the carriers involved.

\section{Materials and Methods}

Rat liver mitochondria were prepared as described previously. The mitochondria were loaded with either $\left[{ }^{14} \mathrm{C}\right]$ citrate (plus isocitrate) as described by Robinson, Williams, Halperin and Leznoff [10] or with $\left[{ }^{14} \mathrm{C}\right] \mathrm{L}$-malate as described by Robinson and Williams [9].

* Present address: Department of Zoology, University of Sheffield, S102 TN, England. 
Table 1. Inhibition of citrate $/\left[{ }^{14} \mathrm{C}\right]$ citrate and the phosphate $/\left[{ }^{14} \mathrm{C}\right]$ L-malate exchange ${ }^{2}$

\begin{tabular}{lll}
\hline Inhibitor & \multicolumn{2}{l}{ Inhibition } \\
\cline { 2 - 3 } & citrate/ & phosphate/ \\
& {$\left[{ }^{14} \mathrm{C}\right]$ citrate } & {$\left[{ }^{14} \mathrm{C}\right]$ L-maiate } \\
& $(\%)$ & $(\%)$ \\
\hline
\end{tabular}

Benzene substituted

with three or more carboxyl groups

1,2,3-benzenetricarboxylate

5-nitro 1,2,3-benzenetricarboxylate

5-amino 1,2,3-benzenetricarboxylate

1,2,3,4-benzenetetracarboxylate

1,2,4,5-benzenetetracarboxylate

1,2,3,5-benzenetetracarboxylate

benzenehexacarboxylate

benzenepentacarboxylate

1,4,5-benzenetricarboxylate

1,3,5-benzenetricarboxylate

5-acetamido 1,2,3-benzenetricarboxylate

$\begin{array}{rc}92 & 19 \\ 77 & 9 \\ 47 & \text { N.T. } \\ 43 & 11 \\ 42 & \text { N.T. } \\ 33 & 6 \\ 28 & 3 \\ 26 & -8 \\ 6 & -8 \\ 3 & 4 \\ 3 & 18\end{array}$

\section{Benzene and pyridine dicarboxylates}

2,3-pyridinedicarboxylate

2,6-pyridinedicarboxylate

1,2-benzenedicarboxylate (phthalate)

4-bromoisophthalate

2-nitroisophthalate

1,3-benzenedicarboxylate (isophthalate)

$o$-(carboxycarbonyl) benzoate (phthalonate)

2,6-pyridine- $\mathrm{N}$-oxidedicarboxylate

3-nitrophthalate

$\begin{array}{cc}47 & 43 \\ 42 & -2 \\ 35 & 35 \\ 31 & 20 \\ 25 & \text { N.T. } \\ 24 & 18 \\ 19 & 16 \\ 16 & 2 \\ -7 & 29\end{array}$

Miscellaneous aromatic acids

$m$-iodobenzoate

p-iodobenzoate

$m$-bromobenzoate

$64 \quad 10$

$p$-iodophenylacetate

60.13

$o$-sulphobenzoate

p-bromophenylacetate

$p$-bromobenzoate

$o$-iodophenylacetate

$o$-iodobenzoate

3-nitro-1,8-naphthalate

$p$-bromomandelate

$m$-sulphobenzoate

o-nitrobenzenesulphonate

2-phenylsuccinate

o-bromobenzoate

N.T. 
Table 1 (continued)

\begin{tabular}{|c|c|c|}
\hline \multirow[t]{2}{*}{ Inhibitor } & \multicolumn{2}{|l|}{ Inhibition } \\
\hline & $\begin{array}{l}\text { citrate/ } \\
{\left[{ }^{14} \mathrm{C}\right] \text { citrate }} \\
(\%)\end{array}$ & $\begin{array}{l}\text { phosphate/ } \\
{\left[{ }^{14} \mathrm{C}\right] \text { L-malate }} \\
(\%)\end{array}$ \\
\hline \multicolumn{3}{|l|}{$\begin{array}{l}\text { Aliphatic compounds } \\
\text { with three or more carboxyl groups }\end{array}$} \\
\hline $\begin{array}{l}\text { 2-ethylcitrate } \\
\text { 2-propylcitrate } \\
\text { cis,cis,cis,cis,-1,2,3,4- } \\
\quad \text { cyclopentanetetracarboxylate } \\
\text { 1,2,3,4-butanetetracarboxylate } \\
\text { trans-aconitate } \\
\text { 1,4,5-pentanetricarboxylate }\end{array}$ & $\begin{array}{r}58 \\
50 \\
\\
35 \\
14 \\
9 \\
1\end{array}$ & $\begin{array}{r}1 \\
12 \\
-2 \\
1\end{array}$ \\
\hline \multicolumn{3}{|l|}{ Miscellaneous } \\
\hline $\begin{array}{l}\text { 2-oxo-hexanedioic acid } \\
\text { 4-oxo-4H-pyran-2,6-dicarboxylate (chelidonate) } \\
\text { glutarate } \\
\text { L-malate } \\
\text { L-cysteate } \\
\text { iodoacetate } \\
\text { o-nitrophenylarsenate } \\
\text { glutaconate } \\
\text { cis-1,2-cyclohexanedicarboxylate } \\
\text { 4-(hydroxymethylene)-glutaconate- } \gamma \text {-lactone } \\
\text { (coumalate) } \\
\text { 1,2,3-propanetriphosphonate } \\
\text { benzenediphosphonate }\end{array}$ & $\begin{array}{r}30 \\
30 \\
24 \\
24 \\
23 \\
22 \\
11 \\
8 \\
8\end{array}$ & $\begin{array}{l}11 \\
\text { N.T. } \\
2 \\
- \\
19 \\
4 \\
3 \\
7 \\
25 \\
\text { N.T. } \\
\text { N.T. } \\
\text { N.T. }\end{array}$ \\
\hline \multicolumn{3}{|l|}{ Substituted malonates } \\
\hline $\begin{array}{l}\text { 2-p-iodobenzylmalonate } \\
\text { 2-(5'-bromoamylmalonate) } \\
\text { 2-oxomalonate (mesoxalate) } \\
\text { 2-benzylmalonate } \\
\text { 2-n-butylmalonate } \\
\text { 2-phenylmalonate } \\
\text { malonate } \\
\text { 2-n-pentylmalonate } \\
\text { 2-cinnamylidinemalonate }\end{array}$ & $\begin{array}{r}89 \\
39 \\
35 \\
35 \\
25 \\
15 \\
12 \\
12 \\
-4\end{array}$ & $\begin{array}{r}108 \\
115 \\
5 \\
96 \\
101 \\
83 \\
3 \\
116 \\
88\end{array}$ \\
\hline
\end{tabular}

a Experiments were performed as described in Materials and Methods using the inhibitors at $10 \mathrm{~mm}$ final concentration. The chemicals are listed in order of their potency in inhibiting citrate $/\left[{ }^{14} \mathrm{C}\right]$ citrate exchange.

Mitochondria loaded with $\left[{ }^{14} \mathrm{C}\right]$ citrate were added to $1-\mathrm{ml}$ incubations of a medium containing $125 \mathrm{~mm} \mathrm{KCl}, 20 \mathrm{mM}$ Tris- $\mathrm{Cl}, \mathrm{pH} 7.4$ at $0^{\circ} \mathrm{C}$. The inhibitors were added at $10 \mathrm{~mm}$ final concentration as the potassium salts at $\mathrm{pH} 7.4$ in the presence of $2 \mathrm{~mm}$ 
citrate. Controls were performed with no added inhibitors or citrate and with citrate alone as described in [10]. After incubation at $0^{\circ} \mathrm{C}$ for $2 \mathrm{~min}$ the mitochondria were separated by centrifugation as previously described [10] and samples of supernatant and pellet prepared for counting of $\left[{ }^{14} \mathrm{C}\right]$ citrate. Results are expressed as percentage exchange in the given time period as defined previously $[9,10]$. In the case of mitochondria loaded with $\left[{ }^{14} \mathrm{C}\right] \mathrm{L}$-malate, incubations were performed at $10^{\circ} \mathrm{C}$ for $2 \mathrm{~min}$ using $5 \mathrm{~mm}$ inorganic phosphate as exchanger with the inhibitors added at $10 \mathrm{~mm}$ final concentration. Under these conditions the initial rate of citrate $/\left[{ }^{14} \mathrm{C}\right]$ citrate exchange would be about 2 mmoles per min per $\mathrm{mg}$ of protein [12] and a similar value would be found for phosphate $/\left[{ }^{14} \mathrm{C}\right]$ L-malate exchange [9]. However, after 2 min the percentage exchange in the control mitochondria would be approaching equilibrium $[9,12]$ and the effects reported in Table 1 do not refer to initial rates. Such initial rate determinations were not made in the screening program reported here and consequently the relative potencies of the inhibitors tested cannot be reported as values of $K_{i}$ as would be desirable. The numerical values of Table 1 therefore provide only a semi-quantitative indication of inhibitor potency. When the percentage inhibition exceeds $100 \%$, it indicates that the amount of label appearing in the external medium during the incubation is less than in control experiments where no exchanging anion is added. When the inhibition is preceeded by a negative sign, it indicates that the amount of label appearing in the external medium during the incubation time exceeds that in control experiments where the exchanging anion alone (i.e., $2 \mathrm{~mm}$ citrate or $5 \mathrm{~mm}$ phosphate) is added.

Inhibitors were obtained either from $\mathrm{K}$ and $\mathrm{K}$ Rare Chemicals, Plainview, New York or the Aldrich Chemical Company, Milwaukee, Wisconsin. 2-n-Pentylmalonic acid and 2-(5'-bromoamyl)malonic acid were prepared by hydrolysis of the diethyl esters. 2-Ethylcitrate was purified as described previously [10]. 5-Nitro-, 5-amino- and 5-acetamido-1,2,3-benzenetricarboxylic acid were prepared by substitution of 1,2,3benzenetricarboxylate [4].

\section{Results \\ Inhibition of Citrate $\left[{ }^{14} \mathrm{C}\right]$ Citrate Exchange}

When the exchange of citrate with $\left[{ }^{14} \mathrm{C}\right]$ citrate was monitored as described in Materials and Methods, it was found that 1,2,3-benzenetricarboxylate was the best inhibitor (Table 1). Modification of this compound with a 5 -nitro group reduced its inhibitory potency while a 5-amino group reduced it even further. 5-Acetamido-1,2,3-benzenetricarboxylate, however, was almost without effect. The requirement for adjacent carboxyl groups is shown by the lack of inhibition by either the 1,4,5- or 1,3,5-benzenetricarboxylates. Introduction of further carboxyl groups reduces the observed inhibition as does removal of a carboxyl group as seen with the benzene tetracarboxylates and dicarboxylates (phthalate and isophthalate). Replacement of a carboxyl with a nitro group as in 3-nitrophthalate or 2-nitroisophthalate likewise reduces the observed inhibition. However, the pyridine analogues of isophthalate and phthalate were slightly more effective than the benzenedicarboxylate. It was not possible to obtain any pyridinetricarboxylate which would have made an interesting comparison with benzenetricarboxylate. 
Among the other aromatic compounds it was found that the halogenated benzoates and phenylacetates were quite effective as inhibitors, the $m$ and $p$-substituted rings being more potent than the $o$-substituted compounds. It has been found that the inhibition brought about by these compounds is much less reversible than that seen with 1,2,3-benzenetricarboxylate [11] so that the mode of inhibition is not strictly competitive, as with the $1,2,3-$ benzenetricarboxylates. The iodo-substituted compounds are more effective in general than the bromo-substituted compounds for $o-, m$ - and $p$-substituted benzoates and phenylacetates. $o$-Sulphobenzoate was a better inhibitor than $m$-sulphobenzoate.

The aliphatic carboxylates did not show any surprising results. 2Ethylcitrate and 2-propylcitrate were both effective inhibitors as had been shown previously [10], while 1,4,5-pentanetricarboxylate, 1,2,3,4-butanetetracarboxylate and trans-aconitate were poor inhibitors. Cis-cis-cis-cis1,2,3,4-cyclopentanetetracarboxylate was unusual in its ability to inhibit. Previously it had been shown that tricarballylate (1,2,3-propanetricarboxylate) was a good substrate for the transporting system so it was interesting to note that neither glutarate nor glutaconate were able to inhibit to any great extent. The triphosphono-analogue of tricarballylate did not inhibit, neither did cyclohexane dicarboxylate.

2-p-Iodobenzylmalonate was alone among the substituted malonates in being a good inhibitor of citrate transport, the iodine function obviously being important since 2-benzylmalonate was not nearly as effective.

\section{Inhibition of Phosphate $\left[{ }^{14} \mathrm{C}\right] \mathrm{L}-$ Malate Exchange}

None of the carboxyl-substituted benzenes were very effective as inbibitors of the dicarboxylate transporting system measured by phosphate/ $\left[{ }^{14} \mathrm{C}\right] \mathrm{L}$-malate exchange. This applied to the first, second and third categories in Table 1 with one striking exception, 3-nitro-1,8-napththalate. This special case will be discussed later. It will be noted that phthalate and 2,3-pyridinedicarboxylate were better inhibitors than isophthalate and 2,6-pyridinedicarboxylate. Halogenated benzoates and phenylacetates were not good inhibitors of this system but interestingly $o$-sulphobenzoate, which is the sulpho-analogue of phthalate, was effective to a much greater degree than $m$-sulphobenzoate, the sulpho-analogue of isophthalate. The most potent inhibitors among the substituted malonates are found to be 2-n-pentylmalonate, 2-(5'-bromoamyl)malonate, 2-n-butylmalonate and 2-benzylmalonate. 2-Phenylmalonate was much more effective than 2-phenylsuccinate. 


\section{$p$ - and m-Iodobenzoate Inhibition of Exchanges}

2-Benzylmalonate differed markedly from 2-p-iodobenzylmalonate in its inhibitory properties. It was a good inhibitor of phosphate $/\left[{ }^{14} \mathrm{C}\right] \mathrm{L}$-malate exchange but had much less effect on citrate $\left[{ }^{14} \mathrm{C}\right]$ citrate exchange and 2-oxoglutarate $/\left[{ }^{14} \mathrm{C}\right]$ L-malate exchange. Its properties were, therefore, more akin to those of 2 -n-pentylmalonate.

Since $p$-iodobenzylmalonate differed in its inhibitory properties from benzylmalonate, a number of halogenated aromatic acids were tested on these systems. It was found that $p$ - and $m$-iodobenzoate were quite inhibitory to citrate/[ $\left.{ }^{14} \mathrm{C}\right]$ citrate exchange (Fig. 1) while $o$-iodobenzoate and $p$-bromobenzoate were not as effective. When phosphate $/\left[{ }^{14} \mathrm{C}\right] \mathrm{L}$-malate exchange was measured, $p$-iodobenzoate had little effect while $m$-iodobenzoate had a biphasic effect, the inhibition observed at low concentrations being reversed at higher concentrations. $m$-Iodobenzoate at low concentrations showed a consistent stimulation of 2-oxoglutarate $/\left[{ }^{14} \mathrm{C}\right] \mathrm{L}$-malate exchange which was reversed at higher concentrations. Again, $p$-iodobenzoate was not effective on this system.

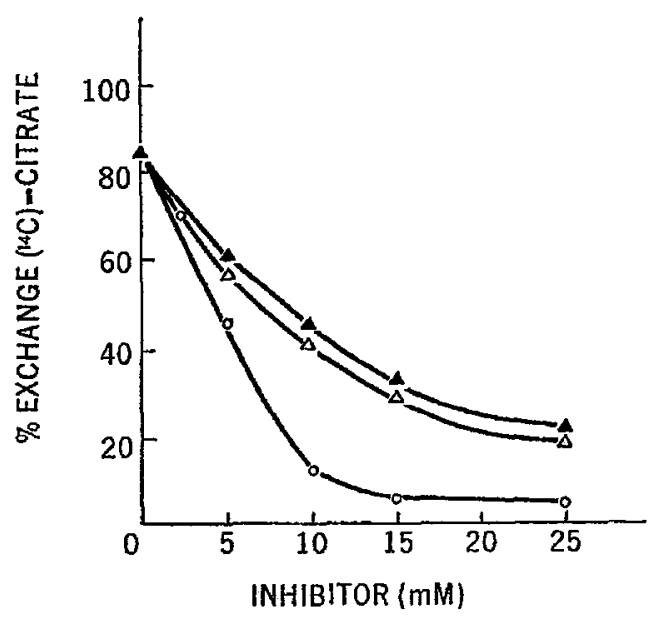

Fig. 1. The sensitivity of citrate/ $\left[{ }^{14} \mathrm{C}\right]$ citrate exchange in rat liver mitochondria to the inhibitors $p$-iodobenzylmalonate, $m$ - and $p$-iodobenzoate. Rat liver mitochondria $(8 \mathrm{mg}$ protein aliquots) loaded with $\left[{ }^{14} \mathrm{C}\right]$ citrate were added to $1-\mathrm{ml}$ incubations of a medium containing $125 \mathrm{mM} \mathrm{KCl}, 20 \mathrm{mM}$ Tris-Cl and $1 \mathrm{mM}$ citrate, $\mathrm{pH} 7.4$ at $10^{\circ} \mathrm{C}$. Control incubations were carried out in the same medium in the absence of the $1 \mathrm{~mm}$ citrate. Inhibitors were included at the concentrations shown; $m$-iodobenzoate $(\Delta-\Delta), p$-iodobenzoate $(a-a), p$-iodobenzylmalonate $(0-0)$. After addition of the mitochondria, the incubations were allowed to stand for $2 \mathrm{~min}$, after which the mitochondria were separated by centrifugation and samples of the supernatant were prepared for counting as described previously [3]. An unseparated sample was also prepared for counting to allow calculation of the total $\left[{ }^{14} \mathrm{C}\right]$ citrate in each incubation. The extent of the exchange of label over the time period was expressed as percentage exchange. This is defined as: (cpm in supernatant of incubation - $\mathrm{cpm}$ in supernatant of control incubation)/cpm in pellet of control incubation $\times 100 / 1$ 


\section{Reversibility of Exchange Inhibition}

To determine whether the inhibition by the iodinated analogues used was of the competitive type, experiments were performed to test the reversibility of the observed inhibition. Rat liver mitochondria loaded with $\left[{ }^{14} \mathrm{C}\right]$ citrate were added to incubations at $10^{\circ} \mathrm{C}$ containing the inhibitors only. After a 1-min interval, citrate was added at increasing concentrations and the incubation was allowed to stand a further $2 \mathrm{~min}$ before separation of the mitochondria by centrifugation as described in [9]. It was found (Fig. 2) that inhibition by the $p$-iodobenzylmalonate and $m$-iodobenzoate was far less reversible by citrate than the inhibition by 1,2,3-benzenetricarboxylate when the inhibitors were used at 25 and $12.5 \mathrm{~mm}$. $m$-Iodobenzoate alone caused some exchange of labelled citrate so the curve for this inhibitor does not begin at the horizontal axis. However, at $5 \mathrm{~mm}$ inhibitor (Fig. 3) the inhibition of p-iodobenzylmalonate was almost as reversible as that by 1,2,3-benzenetricarboxylate, whereas the $m$-iodobenzoate showed some reversibility but was by no means completely reversible. $p$-Iodobenzoate behaved in the same manner as $m$-iodobenzoate.
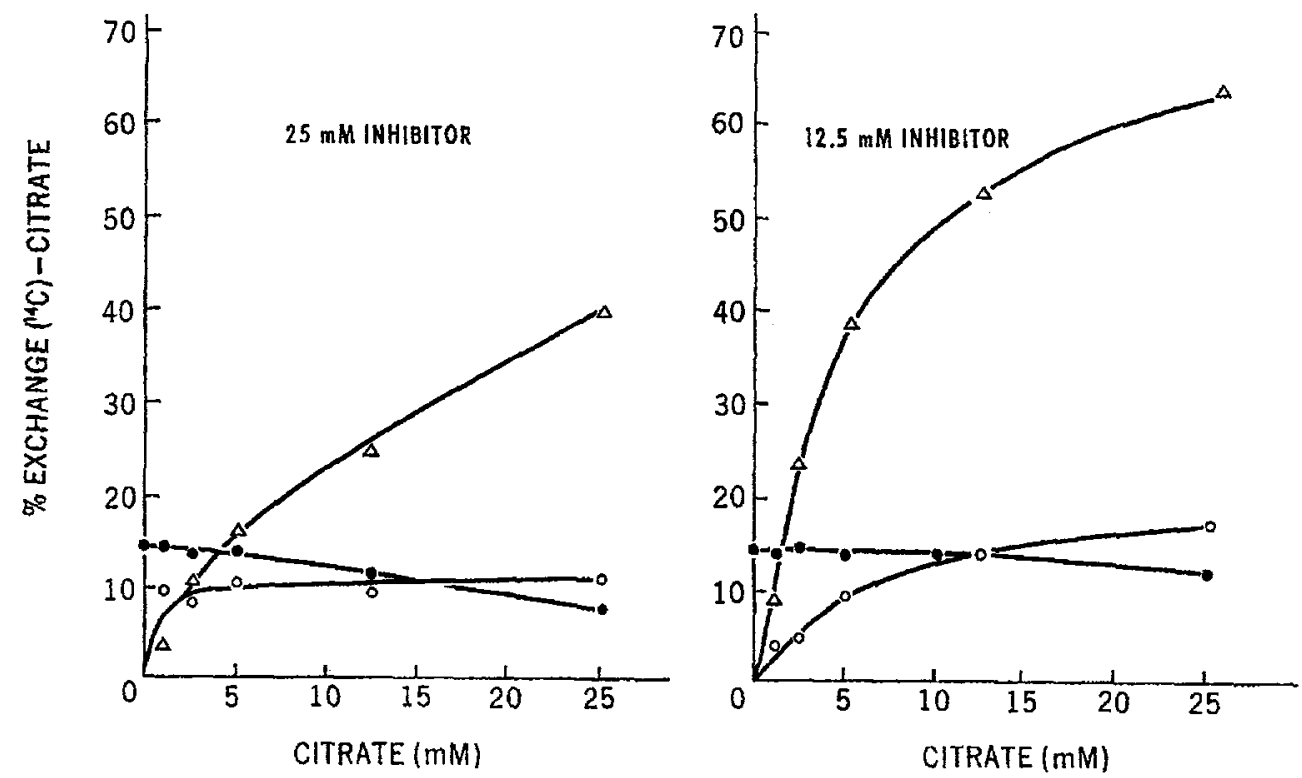

Fig. 2. The reversibility of the inhibition by $1,2,3$-benzenetricarboxylate, $m$-iodobenzoate and $p$-iodobenzylmalonate of citrate $/\left[{ }^{14} \mathrm{C}\right]$ citrate exchange by citrate at $12.5 \mathrm{~mm}$ and $25 \mathrm{~mm}$ of the inhibitors. Rat liver mitochondria (7.8 protein aliquots) loaded with $\left[{ }^{14} \mathrm{C}\right]$ citrate were added to $1-\mathrm{ml}$ incubations of a medium containing $125 \mathrm{mM} \mathrm{KCl}$, $20 \mathrm{~mm}$ Tris-Cl, pH 7.4 at $10^{\circ} \mathrm{C}$. The inhibitors $1,2,3$-benzenetricarboxylate $(\Delta-\Delta)$, $p$-iodobenzylmalonate $(\circ-0)$, and $m$-iodobenzoate $\left(-\bullet_{-}\right)$were present at either 12.5 or $25 \mathrm{~mm}$ concentration. After $1 \mathrm{~min}$, citrate was added at increasing concentrations $(0$ to $25 \mathrm{~mm}$ ) and the incubations were allowed to stand another 2 min before separation of the mitochondria by centrifugation and preparation of supernatants for counting as described previously [3]. Controls were performed as described in the text so that the results could be expressed in terms of percentage exchange 


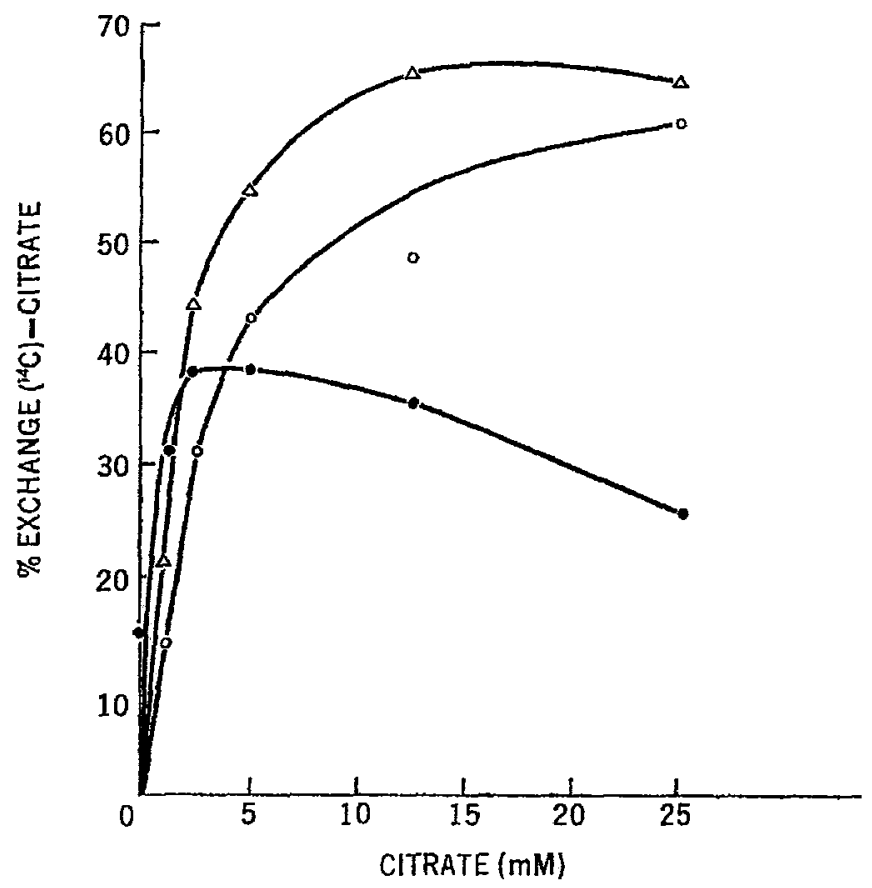

Fig. 3. The reversibility of the inhibition by $1,2,3$-benzenetricarboxylate, $m$-iodobenzoate and $p$-iodobenzylmalonate of citrate $/\left[{ }^{14} \mathrm{C}\right]$ citrate exchange by citrate at $5 \mathrm{~mm}$ of the inhibitors. The experiment was carried out as described for Fig. 2 using $5 \mathrm{~mm}$ of the

inhibitors $1,2,3$-benzenetricarboxylate $(\Delta-\Delta), p$-iodobenzylmalonate $(0-0)$, and $m$-iodobenzoate (•-•)

\section{Discussion}

\section{Inhibition of Tricarboxylate Transport}

The natural substrates for the citrate transporting system of rat liver mitochondria are citrate, cis-aconitate and threo- $\mathrm{D}_{s}$ isocitrate $[2,7]$. All three substrates are transported at similar rates and similar $K_{m}$ values have been obtained for the transport of the three compounds. In addition, tricarballylate (1,2,3-propanetricarboxylate) is a good substrate for this system [10], having similar rates of transport and $K_{m}$ to the three natural substrates (B. H. Robinson, unpublished observations). On the other hand, transaconitate is not transported by this system, neither is it an inhibitor, so that the presence of a cis-carboxyl configuration is necessary if the tricarboxylate is to have affinity for the transport system. The postulate of Chappell and Haarhoff [1] that the tricarboxylate carrier accepts transcarboxyls was based on the affinity of this carrier for the tartrates as observed by the ammonium swelling technique. The assumption was made that mesotartrate had no affinity for the tricarboxylate transporting system but this is probably not the case [3] since mesotartrate is a good activator 
of isocitrate oxidation. In view of the potent inhibition shown by $1,2,3-$ benzenetricarboxylate with respect to citrate transport we propose that the active site of the carrier involves binding sites for cis-carboxyl groups. This implies that citrate must go into a relatively fixed configuration before attachment to the carrier protein. The presence of further carboxyl groups on 1,2,3-benzenetricarboxylate reduced the effectiveness of the inhibitor as does the different positioning of the three carboxyls on the aromatic nucleus.

The behavior of the iodobenzoic acids as inhibitors of the citrate transporting system is somewhat puzzling. In contrast to $p$-iodobenzylmalonate, they do not effectively block either the 2-oxoglutarate or dicarboxylate transporting systems and the inhibition of citrate transport appears to be considerably less reversible. It is unlikely that $m$ - and $p$ iodobenzoate bind to the transport system in a covalent manner in view of the non-lability of the halogens substituted on the benzene ring. It is more likely that a hydrophobic region associated with the carrier system is capable of tightly binding these compounds with a subsequent loss in catalytic activity. Experiments in which mitochondria were treated with $m$-iodobenzoate and then washed in buffer to remove the inhibitor present in solution still showed a $70 \%$ inhibition of citrate/ $\left[{ }^{14} \mathrm{C}\right]$ citrate exchange when compared with untreated mitochondria. Since $p$-iodobenzylmalonate is alone among the substituted malonates in providing a strong inhibition of the citrate transporting system but on the other hand gives a more reversible inhibition than the substituted benzoates, it may be that this compound combines a binding of the halogenated benzene ring to the hydrophobic portion of the carrier system which has affinity for the iodobenzoates together with the binding of two carboxyl groups to the citrate binding site.

It seems then that inhibition of the citrate transporting system can be brought about in two ways: (a) either three carboxyl-binding sites can be bound by the three carboxyls of the inhibitor as with 2-ethylcitrate, 2propylcitrate and 1,2,3-benzenetricarboxylate, or (b) the hydrophobic region binds a $m$ - or $p$-halogenated aromatic ring at the same time as binding one carboxyl binding site, as with the iodobenzoates, or two carboxyl binding sites, as with $p$-iodobenzylmalonate.

\section{Inhibition of Dicarboxylate Transport}

The natural substrates for the dicarboxylate transporting system are succinate and L-malate [1] which in the normal course of events could exchange across the mitochondrial membrane for each other or for in- 
Table 2. Intercarboxyl distances in dicarboxylic acids a

\begin{tabular}{ll}
\hline Acid & $\begin{array}{l}\text { Intercarboxyl } \\
\text { distance } \\
\text { (nm) }\end{array}$ \\
\hline malate & 0.25 \\
substituted malonates & 0.24 \\
1,8-naphthalate & 0.24 \\
phthalate & 0.28 \\
\hline
\end{tabular}

a The distances between the carbon atoms of adjacent carboxyl groups was measured using Drieding models.

organic phosphate, though it has been shown that other dicarboxylic acid analogues are able to be transported by this system. Compounds with adjacent cis-carboxyls such as 2,3-pyridinedicarboxylate, cis-1,2-cyclohexanedicarboxylate and phthalate all show some inhibitory activity towards this transporting system but none of these is as potent as the substituted malonates. Apart from the substituted malonates, the highest activity is shown by 3-nitro-1,8-naphthalate. This finding may be rationalized on the basis of the fact that the inter-carboxyl distance in this compound more closely resembles that of malate and the substituted malonates than that of less active inhibitors such as phthalate (Table 2).

Halogenated benzoates are not effective so it would appear that no hydrophobic pocket analogous to the one proposed for the citrate system exists here. However, it does seem that an aromatic or aliphatic chain is substituted onto the malonate in the 2 position is necessary for effective inhibition of this transporting system. How then does the dicarboxylate carrier site differ from that in the citrate transporting system, both systems being inhibited strongly by $p$-iodobenzylmalonate? First, it seems that there are two cis-carboxyl binding sites both of which have to be found if a good inhibition is to be seen. Second, benzylmalonate is as effective as $p$-iodobenzylmalonate so the effect of a halogen substitution is less important.

We thank Mrs. J. Oei for skilled technical assistance. B.H.R. was the holder of a Medical Research Council of Canada Postdoctoral Fellowship.

This work was supported by grants from the Medical Research Council of Canada (M.L.H. (Ma-3363) and G.R.W. (MT-3182)), and a grant from the National Research Council of Canada to C.C.L. 


\section{References}

1. Chappell, J. B., Haarhoff, K. N. 1966. The penetration of the mitochondrial membrane by anions and cations. In: Biochemistry of Mitochondria, E. C. Slater, Z. Kaniuga and L. Wojtcak, editors. p. 75. Academic Press Inc., New York, and Polish Scientific Publishers, Warsaw.

2. Chappell, J. B., Robinson, B. H. 1968. Penetration of the mitochondrial membrane by tricarboxylic acid anions. Biochem. Soc. Symp. 27:123.

3. Ferguson, S. M. F., Williams, G. R. 1966. The effect of malate and other dicarboxylic acids on mitochondrial isocitrate metabolism. J. Biol. Chem. 241:3969.

4. Prelog, V., Schneider, R. 1949. Untersuchungen über Organextrakte. Über die Lage der zweiten Carbonyl-Gruppe im Diketon D (Oxo-cis-tetrahydro-jonen) aus dem Harn trächtiger Stuten. Helv. Chim. Acta 32:1632.

5. Quagliariello, E., Palmieri, F., Prezioso, G., Klingenberg, M. 1969. Kinetics of succinate uptake by rat-liver mitochondria. F.E.B.S. 4:251.

6. Robinson, B. H., Chappell, J. B. 1967. The inhibition of malate, tricarboxylate and oxoglutarate entry into mitochondria by $2-n$-butylmalonate. Biochem. Biophys. Res. Commun. 28:249.

7. Robinson, B. H., Chappell, J. B. 1970. The kinetics of tricarboxylate anion oxidation by rat liver mitochondria in relation to the availability of L-malate. Biochim. Biophys. Acta 205:300.

8. Robinson, B. H., Williams, G. R. 1969. The effect on mitochondrial oxidations of inhibitors of the dicarboxylate anion transporting system. F.E.B.S. 5:301.

9. Robinson, B. H., Williams, G. R. 1970. The sensitivity of dicarboxylate anion exchange reactions to transport inhibitors in rat-liver mitochondria. Biochim. Biophys. Acta 216:63.

10. Robinson, B. H., Williams, G. R., Halperin, M. L., Leznoff, C. C. 1970 . The effects of 2-ethylcitrate and tricarballylate on citrate transport in rat liver mitochondria and fatty acid synthesis in rat white adipose tissue. Europ. J. Biochem. 15:263.

11. Robinson, B. H., Williams, G. R., Halperin, M. L., Leznoff, C. C. 1971. The sensitivity of the exchange reactions of tricarboxylate, 2-oxoglutarate and dicarboxylate transporting systems of rat liver mitochondria to inhibition of 2-pentylmalonate $p$-iodobenzylmalonate and benzene 1,2,3-tricarboxylate. Europ. J. Biochem. 20:65.

12. Robinson, B. H., Williams, G. R., Halperin, M. L., Leznoff, C. C. 1971. Factors affecting the kinetics and equilibrium of exchange reactions of the citrate-transporting system of rat liver mitochondria. J. Biol. Chem. 246:5280. 